\title{
A Precariedade Das Condições De Trabalho Dos Entregadores Por Aplicativos
}

Felipe Labruna*

Pontifícia Universidade Católica de São Paulo, Programa de Pós-Graduação em Direito, Perdizes-SP, Brasil.

iD https://orcid.org/0000-0003-3844-3301

\author{
Alvaro de Azevedo Gonzaga** \\ Pontifícia Universidade Católica de São Paulo, Programa de Pós-Graduação em Direito, Perdizes-SP, \\ Brasil. \\ iD https://orcid.org/0000-0002-4051-0748 \\ Marco Aurélio Barreto Lima*** \\ Pontifícia Universidade Católica de São Paulo, Programa de Pós-Graduação em Direito, Perdizes-SP, \\ Brasil.
}

Resumo: Este artigo científico tem a intenção de aprofundar as discussões sobre o fenômeno da transformação das relações do trabalho por meio de plataformas digitais ("aplicativos" ou "apps") e a consequente precarização das condições do trabalho e degradação dos direitos sociais dos entregadores, trazendo novos elementos para a propositura de um ambiente regulatório mais agregador e que assuma as novas dificuldades trazidas por estas tecnologias. Esta mudança tecnológica diz respeito a uma inovadora tendência mundial de administração, manejo e domínio das relações de trabalho em ambientes virtuais, causando efeito prejudicial ao trabalhador de entrega conhecido como "uberização" de sua força de trabalho. Neste sentido, o presente trabalho se propõe a fazer breve levantamento legislativo sobre o histórico de concessão e regulação do Direito do Trabalho no Brasil e, em seguida, analisar por meios teóricos como o desempenho do trabalho por meio das plataformas digitais/aplicativos existentes exige uma maior regulação estatal de sua prática e utilização.

Palavras-chave: Aplicativos de delivery. Direitos sociais. Direito do trabalho. Entregadores. "Uberização".

\footnotetext{
* Mestrando e graduado em Direito pela PUC-SP. Servidor do Tribunal de Justiça do Estado de São Paulo. E-mail: fe.labruna@gmail.com

** Livre Docente em Filosofia do Direito pela PUC-SP. Pós-Doutorados na Faculdade de Direito da Universidade Clássica de Lisboa e na Universidade de Coimbra. Doutor em Direito pela PUC-SP. Professor do Programa de Pós-Graduação em Direito da PUC-SP. E-mail: alvarofilosofia@hotmail.com

*** Mestrando e graduado em Direito pela Pontifícia Universidade Católica de São Paulo (PUC-SP). Email: marcolima.barreto@gmail.com
}

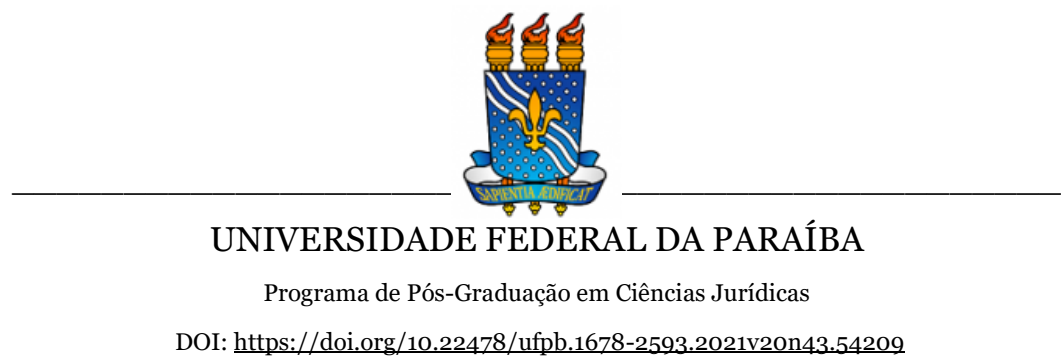




\title{
A Precariedade Das Condições De Trabalho Dos Entregadores Por Aplicativos
}

\author{
Felipe Labruna
}

Alvaro de Azevedo Gonzaga

Marco Aurélio Barreto Lima

\section{INTRODUÇÃO}

O Trabalho pode ser definido como um conjunto de ações básicas, objetivas, mecânicas, que se encarregam de prover o sustento do ser humano, atendendo suas necessidades essenciais de sobrevivência. No entanto, o Trabalho diz respeito à produção para o mundo ordinário, ou seja, o mundo palpável, concreto e durável criado pela figura humana (ARENDT, 1983). No atual momento, em que as condições de isolamento social se tornam mandatórias, as inovações da tecnologia possibilitam que parte dos trabalhadores permaneça em suas residências ou ambientes de trabalho, enquanto outra parcela está nas ruas, conduzindo motocicletas ou bicicletas e colocando a própria integridade em risco para alimentar um sistema de entregas de encomendas variadas realizadas por meio de plataformas digitais denominadas aplicativos (apps).

A atividade do homem, em matéria de trabalho, gera valor a ser introduzido no ambiente coletivo, afinal estamos todos inseridos em sociedade. Acredita-se que muitas atividades laborais correm o risco de serem extintas ou substituídas pela robotização e automação nos próximos anos. Nesta linha, diversas funções hoje exercidas pelo homem deixarão de ser imprescindíveis e serão gradualmente 
substituídas por outras, ainda que essa substituição tenha uma probabilidade maior de ocorrer primeiro em países de desenvolvidos do que em países subdesenvolvidos, em razão das já conhecidas deficiências educacionais estruturais destes últimos. Entretanto, os ambientes virtuais proporcionados pelas plataformas digitais podem favorecer o rápido crescimento da quantidade de vagas de trabalho e ocupação, já que tais instrumentos tecnológicos proporcionam a concretização da ligação entre fornecedores e clientes, com o racionamento instantâneo de indivíduos e companhias prestadoras de qualquer tipo de serviço quando há demanda, de forma que todos os recursos empregados sejam otimizados (FLEURY, 2020).

Neste contexto, determinados ofícios se tornam ainda mais relevantes, como por exemplo os criadores e desenvolvedores de software e suas adaptações para aparelhos celulares ("smartphones") denominadas versões "mobiles" ou aplicativos (apps). Profissionais qualificados nestas áreas possuem farta oferta de trabalho em decorrência da escassez de concorrentes. Com isso, acredita-se que nos próximos anos o Brasil terá grande déficit de operadores de tecnologia, capazes de instrumentalizar as novas ferramentas do mundo moderno. ${ }^{1}$ Por outro lado, viabilizando a operação de muitos destes aplicativos, existe outra categoria de trabalhadores, também com demanda crescente, inclusive pela pandemia de covid-19 que assola o mundo desde o final de 2019: os entregadores. Estes profissionais levam os itens adquiridos pelos usuários e clientes por meio de automóveis, motocicletas, bicicletas ou até mesmo a pé, criando o canal entre os que ofertam e os que adquirem alimentos, bens ou serviços (ARAUJO, 2019).

\footnotetext{
${ }^{1}$ De acordo com pesquisa da Associação Brasileira das Empresas de Tecnologia da Informação e Comunicação (Brasscom) para suprir a demanda do setor de software e serviços, será necessário formar 70 mil novos profissionais até 2024. Atualmente, o déficit de 24 mil profissionais da área. Ver: Mercado de tecnologia tem déficit de 24 mil profissionais por ano. Disponível em: $<$ https://oglobo.globo.com/economia/emprego/mercado-de-tecnologia-temdeficit-de-24-mil-profissionais-por-ano-24170633>. Acesso em $1^{\circ}$ de outubro de 2020.
} 
Os trabalhadores de entrega de apps, constantemente associados às marcas com que operam como iFood, Rappi, Uber Eats, James, entre outros, são um grupo de profissionais “uberizados”. Tal denominação surgiu pela primeira vez no Brasil em meados do ano de 2015 para se referir aos motoristas que atuam pelo aplicativo de viagens de automóvel Uber, de maneira eventual e sem vínculo empregatício, até o momento. Há muito debate sobre as penosas condições e conexões de trabalho a que estão submetidos os entregadores de aplicativos, de maneira que tal assunto tem cada vez mais sido tema de pautas jornalísticas e discussões acadêmicas. Determinadas empresas que operam estes apps de entrega têm demonstrado razoável iniciativa para propiciar a melhora das condições de trabalho dos entregadores e, alguns países e cidades, até mesmo estabeleceram regulações específicas para o ofício, muito embora o cenário atual ainda indica que há muito para ser debatido (FLEURY, 2020).

A relevância das plataformas digitais e a necessidade do trabalho dos entregadores de aplicativo se tornam ainda maiores em meio à atual pandemia do novo coronavírus, situação em que o isolamento social é medida de saúde pública recomendada, ou até mesmo obrigatória, e a locomoção dentro das cidades para a realização de compras e contratação de serviços decai consideravelmente. Nestes termos, é necessário ver com bons olhos a regulamentação das condições de trabalho dos profissionais de entrega, aliado ao fato de que o Brasil precisa exercer maior protagonismo em matéria de inovação digital. Para cumprir esta tarefa, é fundamental fomentarmos o debate aqui proposto, criando uma análise sobre o histórico de concessão e regulação do Direito do Trabalho no país. 


\section{BREVE HISTÓRICO DE CONCESSÃO E REGULAÇÃO DO DIREITO DO TRABALHO NO BRASIL}

O Direito do Trabalho é produto tanto das inquietudes sociais promovidas pela Revolução Industrial do século XVIII, que, com o progresso da tecnologia e da ciência conferiram uma inovadora face ao mecanismo de produção de bens no continente europeu; quanto da propaganda humanista, que afirmava a conservação da dignidade do homem que se ocupava com o labor nas indústrias. Assim, o anseio de equipar a ordem jurídica com uma matéria capaz de conduzir as relações individuais e coletivas de trabalho progrediu rapidamente pelo mundo industrializado envolto a novas convicções. As consequências do capitalismo e das premissas da infraestrutura social foram sentidas com bastante força em meio à Revolução Industrial, de tal forma que, no início do século XIX, foi cunhada pela primeira vez a expressão "questão social” (NASCIMENTO, 2014).

Escreveu Martinez (2016, p. 54) sobre o assunto:

O processo construtivo do direito do trabalho e, por consequência, dos demais direitos sociais decorreu do conflito de classes. Sua edificação e crescimento, por outro lado, provieram de uma pletora de acontecimentos historicamente favoráveis. Sem dúvida, no tocante à história constitutiva do direito do trabalho, pode-se dizer que é incrível o poder que as coisas parecem ter quando elas precisam acontecer. $\mathrm{O}$ ramo jurídico ora em análise parece efetivamente ter emergido pela força do inevitável, do inexorável. Ele tinha de acontecer, por isso aconteceu: múltiplos fatores alinharam-se e contribuíram para a edificação dos direitos sociais, especialmente para a construção de um sistema jurídico capaz de proteger os trabalhadores dos abusos perpetrados por seus patrões. Se o direto do trabalho, como regulação normativa de origem estatal ou convencional, não tivesse acontecido, certamente a história que envolvia conflitos entre capital e trabalho seria diferente.

No Brasil, iniciou-se o período liberal do Direito do Trabalho a partir da abolição da escravidão em 1888 e da proclamação da República no ano seguinte, sendo marcada por determinadas iniciativas que, em que pese não possuíssem muito alcance, 
colaboraram para o posterior desenvolvimento da legislação no país. Nos primeiros anos da República a ocorrência de greves era esporádica, tendo os trabalhadores o intuito de reivindicar melhores condições salariais e a redução da jornada de trabalho diária. Entretanto, no início do século XX, as insurgências trabalhistas se intensificaram. A primeira greve de grande repercussão no Brasil se deu no dia 12 de junho de 1917, iniciando no Cotonifício Rodolfo Crespi, no bairro da Mooca, ocasião em que houve o protesto de operários em prol de melhores salários (com aumento de 20\% sobre a remuneração), paralisando o serviço fabril em decorrência do fracasso de uma tentativa de acordo com a empregadora. Tal movimento propagou-se para o interior do estado, de forma que treze municípios foram atingidos e somente no dia 15 de julho foi aceito acordo para majoração de 20\% nos salários, sob a garantia de que nenhum contratado seria demitido em razão da greve (NASCIMENTO, 2014).

Neste cenário, diversas leis trabalhistas nasciam no continente europeu e os reflexos no Brasil eram retraídos, notados somente por alguns pensadores, mas sem que pudessem causar alguma ação governamental. A Constituição da República do Brasil de 1891 não era focada nas questões sociais, e suas linhas-base não tratavam da problemática trabalhista. A primeira Constituição nacional a tratar sobre o tema de Direito do Trabalho foi a de 1934. Desde então, todas Constituições nacionais possuem princípios e regras sobre direitos trabalhistas (LEITE, 2018).

O período entre 1930 a 1945 é considerado um dos grandes momentos da legislação social e trabalhista brasileira. Sobre forte influência do positivismo ortodoxo, Getúlio Vargas, passou a adotar medidas de integração do proletário à sociedade através de providências a favor da proteção do trabalho e da família, ressaltando a ajuda mútua entre empregados e empregadores e a procura por soluções de paz para as divergências. Assim, Getúlio criou o Ministério do Trabalho, Indústria e Comércio, em 26 de novembro de 1930, logo em seguida à vitória da Revolução de 1930. A posição de ministro foi 
assumida por Lindolfo Collor, igualmente positivista ortodoxo e seu Ministério atuou de maneira rápida em três frentes: trabalhista, sindical e previdenciária (SANTOS, 1979).

No campo trabalhista as principais ações foram em 1931, com a concepção do Departamento Nacional do Trabalho, e em 1932, com o estabelecimento de jornada de oito horas diárias na indústria e comércio, a regulação do trabalho exercido pelas mulheres com equiparação de salário, o trabalho dos menores de idade, a instituição da Carteira de Trabalho e das Comissões e Juntas de Conciliação e Julgamento e a normatização do direito ao usufruto de férias. Já na área previdenciária, a partir de 1933 ocorreram amplos progressos. Neste ano foi idealizado o Instituto de Aposentadoria e Pensão dos Marítimos, iniciando processo de reforma e incremento das Caixas de Aposentadoria e Pensão (CAP’s) da década de 1920. No decorrer de cinco anos, a Previdência Social foi desdobrada a quase todos os trabalhadores urbanos, sendo atendida uma antiga queixa dos empregados nas cidades. Por outro lado, o sistema marginalizava determinadas categorias de trabalhadores, a exemplo dos autônomos, trabalhadores domésticos e do campo. ${ }^{2}$ Por conseguinte, referia-se a uma formulação da política social como prerrogativa e não como direito, já que o conceito de cidadania era delineado por limitações políticas (CARVALHO, 2002).

Entretanto, pouco a pouco, a definição e o alcance de materialização do termo "cidadania" passaram a ser deslocados do prisma social para o campo produtivo. A normatização dos ofícios e das profissões, a carteira de anotação profissional e a figura pública do sindicato delimitavam, então, os três critérios para a definição da palavra "cidadania". Assim sendo, os direitos a serem exercidos pelos cidadãos eram consequência dos direitos individuais e exclusivos

2 Os direitos trabalhistas plenos foram conferidos aos trabalhadores rurais e autônomos apenas com o advento da Constituição Federal de 1988. Para trabalhadores domésticos, o reconhecimento de direitos já conquistados pelas demais categorias urbanas na década de 1920, apenas foi efetivada em 2015, com a entrada em vigor Emenda Constitucional no 72 (derivada da PEC 66/2012, ou PEC das Domésticas) e da Lei Complementar $n^{\circ} 150$. 
concedidos às profissões. Além disso, a existência de cada profissão pressupunha a autorização e normatização do Estado. A carteira de trabalho era o apetrecho jurídico que comprovava a existência de um contrato entre a Administração Pública e a "cidadania regulada". Tal carteira de anotação profissional, além de indício de exercício de trabalho, passou a ser propriamente uma certidão de nascimento cívico, já que seu portador passaria a ser considerado cidadão capaz de exercer direitos e contrair obrigações. Desse modo, os direitos evadiam do campo social e passavam a ser determinados pelo cerne da produção sob a ingerência Estatal. Assim ensaiou Santos (1979, p. 68) sobre sua expressão "cidadania regulada":

Por cidadania regulada entendo o conceito de cidadania cujas raízes encontram-se, não em um código de valores políticos, mas em um sistema de estratificação social, e que ademais, tal sistema de estratificação ocupacional é definido por norma legal. Em outras palavras, são cidadãos todos aqueles membros da comunidade que se encontram localizados em qualquer uma das ocupações reconhecidas e definidas em lei.

A extensão da cidadania se faz, pois, via regulamentação de novas profissões e/ou ocupações, em primeiro lugar, e mediante ampliação do espaço dos direitos associados a estas profissões, antes que por expansão dos valores inerentes ao conceito de membro da comunidade. A cidadania está embutida na profissão e os direitos do cidadão restringem-se aos direitos do lugar que ocupa no processo produtivo, tal como reconhecido por lei.

Tornam-se pré-cidadãos, assim, todos aqueles cuja ocupação a lei desconhece. [...] A associação entre cidadania e ocupação proporcionará as condições institucionais para que se inflem, posteriormente, os conceitos de marginalidade e de mercado informal de trabalho [...].

Do ângulo de visão político, o modo de atuar do Governo voltado à esfera sindical foi o ponto central da estratégia de administração pública. A ideologia/filosofia do corpo governista foi visto no primeiro decreto, expedido em 1931, que tratou sobre a sindicalização, sendo muito parecido com o ponto de vista positivista presente no começo do século XX, assim como com a doutrina social da Igreja Católica, que pregava que o Trabalho e Capital deviam se relacionar de forma harmoniosa e que era dever do Estado resguardar 
este equilíbrio, efetivando a função de regulador e de árbitro. Neste contexto, o apetrecho para se operar a harmonia era a organização sindical. Assim sendo, o sindicato não atuava como uma organização para representar os interesses dos operários perante os patrões, mas sim, de colaboração entre estes dois agrupamentos e o próprio Estado. Por causa disso, o sindicato naquele momento não era uma entidade de direito privado, mas sim de direito público, atuando como um verdadeiro órgão técnico governamental de consulta, sendo excluída a pluralidade sindical, que cedeu o seu lugar para a chamada singularidade sindical (CARVALHO, 2002).

A intervenção estatal possuía, neste ponto, duas faces: se de um lado defendia o cidadão por meio da legislação trabalhista, de outro constrangia por meio das leis de conteúdo sindical. Ademais, a proteção do Estado afetava a própria liberdade dos grupos operários, submetendo-os à ingerência do Ministério do Trabalho. Neste prisma, se os trabalhadores contratados ostentavam fraquezas para afrontarem as abusividades de seus patrões, igualmente eram fracos para se oporem às arbitrariedades estatais. Neste cenário. havia claro dilema perante a movimentação operária, à medida em que os operários necessitavam optar entre a proteção proporcionada pelo Estado sem liberdade ou esta mesma liberdade sem qualquer proteção. Desta feita, a problemática primordial era a desigualdades de poderes entre a classe operária e o grupo de patrões (LEITE, 2018).

Uma relevante herança da legislação de cunho sindical do Estado Novo foi a instituição do imposto sindical, idealizada no ano de 1940 e estando vigente até os diais atuais, em que pese várias tentativas de eliminá-lo do ordenamento jurídico. Embora o imposto sindical concedesse fôlego para que grupos sindicais mantivessem sua estrutura burocrática ou até mesmo para oferecer benesses adicionais aos seus associados, tais como amparo médico, odontológico ou advocatício, também motivava a organização dos próprios sindicatos. A adesão ao quadro sindical em si restava prejudicada, afinal era efetuada a cobrança deste imposto perante todos, de forma obrigatória, não obstante somente alguns serem beneficiados. Além 
disso, houve estímulo ao "peleguismo". O termo é oriundo de "pelego", ou seja, o chamado líder sindical que mediava os interesses entre o Estado e os operários. Os pelegos eram cúmplices do Governo e dos patrões, recebendo deles benefícios e favores. Alguns pelegos se apresentavam como eficientes gestores dos recursos sindicais e assim tornavam os sindicatos atrativos em virtude das vantagens que ofereciam. Entretanto, via de regra, eram personagens mal vistos pelos associados mais comprometidos dos sindicatos, em uma tentativa de destituí-los. Em algumas ocasiões, todo o alicerce operário era elidido, de forma que o poder sindical consistia, nesses casos, em um estado-maior sem soldados (CARVALHO, 2002).

Um personagem que restou excluído de toda a sistemática legislativa em prol do trabalho no período da "Era Vargas" foi o trabalhador do campo. O estiramento da legislação social ao trabalhador rural necessitou aguardar o tardio regime militar para ser aplicada. $O$ fato de o trabalho do campo não ter sido contemplado pela legislação trabalhista demonstra, com exatidão a força e influência que ainda exerciam os proprietários rurais. Apesar disso, é inegável que o $1^{\circ}$ período Varguista (1930-1945) foi o grande momento de propagação dos direitos sociais no país, tendo sido instituído nele a base da legislação trabalhista e previdenciária brasileira (NASCIMENTO, 2014).

Grande coleção legislativa foi promulgada neste período, o que culminou com a aprovação da Consolidação das Leis do Trabalho (CLT), por meio do Decreto-Lei n. ${ }^{\circ} 5.452$, de $1^{\circ}$ de maio de 1943 , assinado pelo então presidente Getúlio Vargas enquanto vigorava o Estado Novo (1937-1945), unificando toda legislação trabalhista existente no Brasil até então. A CLT resistiu à redemocratização de 1945 e permanece em vigor até os dias de hoje, ressalvadas suas modificações. Tal coleção legislativa trabalhista foi introduzida em cenário de baixa ou nula participação política do povo e de frágil constância dos direitos civis. Este problema em sua origem e a forma como foram concedidos os benefícios sociais, fizeram com que 
houvesse dúvidas sobre sua definição como vitória de cunho democrático e de certa forma prejudicou sua colaboração para a criação de uma cidadania ativa (CARVALHO, 2002).

Foi a Constituição Cidadã de 1988 quem iniciou novo traçado histórico de direitos sociais no país, irradiando de modo direto no Direito do Trabalho sob o modelo proposto de manutenção do Estado Democrática de Direito. Tal Carta Magna possui inúmeros comandos destinados a tratar dos direitos trabalhistas (individual e coletivo) e aborda o Direito do Trabalho como um dos direitos sociais, o inserindo na parte em que trata dos "Direitos e Garantias Fundamentais". Considerada uma das Constituições mais modernas no campo social, por contemplar os direitos trabalhistas como verdadeiros direitos fundamentais, a Constituição de 1988 trouxe uma enorme preocupação em relação à proteção do trabalho, principalmente em virtude da extensa quantidade de normas constitucionais focadas no campo trabalhista.

Sobre as novas garantias trabalhistas advindas com a promulgação da Constituição Federal de 1988, dispôs Silva (2012, p. 297/298):

Logo, diante do conjunto normativo existente no Brasil na atualidade, observa-se que para além de meramente tutelar interesses dos trabalhadores, existe uma preocupação recorrente em harmonizar de forma otimizada os diferentes conflitos advindos, muitas vezes, da própria relação estabelecida entre empregadores e empregados. A admissão pelo legislador constituinte de 1988, de instrumentos aptos a possibilitar a flexibilização de determinadas condições de trabalho, desde que intermediada a negociação pela entidade coletiva que representa os trabalhadores, mostra-se como uma forma de se tentar ao menos minimizar possíveis efeitos nocivos a própria classe trabalhadora.

Ao mesmo tempo, tal posicionamento estatal fortalece, até mesmo, os próprios órgãos classistas. Dentro desse processo, tais instituições acabam por se afirmar na defesa dos interesses de uma determinada categoria.

O declínio global do modelo socialista ao lado da propagação dos grandes blocos econômicos mundiais do fenômeno da globalização vem fazendo com que se discuta no momento modelos de 
flexibilização, desregulamentação, privatização do Estado, desconstitucionalização e terceirização dos direitos trabalhistas (LEITE, 2018). Neste sentido, surge o questionamento: o Direito do Trabalho vai persistir?

Esta pergunta que já se demonstrava bastante complexa no final do século XX, adentra a década de 2010 com um peso ainda maior. Em diversos espaços territoriais, a permanência de direitos trabalhistas fundamentais, conquistados ao longo dos anos, foi perdendo força e dando espaço à "contratos fluidos" de trabalho, com a introdução em massa dos instrumentos de pejotização e terceirização.

No Brasil, o recente enfraquecimento das correntes políticas sociais-democratas, acompanhado da escalada de movimentos liberais simpatizantes ao neo-fascismo também teve reflexo importante. A aprovação da Reforma Trabalhista em 2017, por meio da Lei ${ }^{0}{ }^{0} 13.467$, que alterou a CLT, bem como os julgamentos sucessivos de ações de controle constitucional abstrato no STF, que permitiram a expansão dos conceitos de terceirização, teletrabalho e livre negociação entre patrões e empregados, por exemplo, representaram, em última medida, um sinal bastante forte sobre como serão os próximos anos para os trabalhadores brasileiros. Em resposta à pergunta anterior, considerando a erosão política dos direitos trabalhistas conquistados e a ratificação jurídica das escolhas ultra-liberalizantes adotadas pelo Estado, o Direito do Trabalho precisará se reinventar para voltar a apresentar resultados satisfatórios, cobrindo novamente os trabalhadores brasileiros que hoje operam à sua margem.

\section{AS CONFIGURAÇÕES DO TRABALHO DE ENTREGA POR MEIO DAS PLATAFORMAS DIGITAIS/APLICATIVOS}

Grande quantidade das plataformas digitais da atualidade, que prestam serviços por meio de websites ou aplicativos para telefone 
celular, apresenta sede em outros países e atuam mundialmente. Algumas delas, como a plataforma de deslocamentos por automóveis Uber, com valor de mercado estipulado em 82 bilhões de dólares, já possuem ações negociadas em bolsas de valores e contam com seus capitais abertos, o que comprova sua relevância, organização e solidez financeira. Entretanto, ainda é escassa a normatização dessas inovadoras tecnologias na esfera do trabalho, tanto a nível nacional quanto global. Neste contexto, referidas empresas de gestoras de apps agem de maneira diferente em cada um dos países que utilizam suas facilidades (SABINO, 2019).

No caso do Brasil, as condições do vínculo de emprego estão constantes nos artigos $2^{\circ}$ e $3^{\circ}$ da Consolidação das Leis do Trabalho:

\footnotetext{
Art. $2^{\mathrm{O}}$ - Considera-se empregador a empresa, individual ou coletiva, que, assumindo os riscos da atividade econômica, admite, assalaria e dirige a prestação pessoal de serviço.

$\S 1^{\mathrm{o}}$ - Equiparam-se ao empregador, para os efeitos exclusivos da relação de emprego, os profissionais liberais, as instituições de beneficência, as associações recreativas ou outras instituições sem fins lucrativos, que admitirem trabalhadores como empregados.

$\S 2^{\circ}$ - Sempre que uma ou mais empresas, tendo, embora, cada uma delas, personalidade jurídica própria, estiverem sob a direção, controle ou administração de outra, ou ainda quando, mesmo guardando cada uma sua autonomia, integrem grupo econômico, serão responsáveis solidariamente pelas obrigações decorrentes da relação de emprego.

$\S 3^{\mathrm{o}}$ - Não caracteriza grupo econômico a mera identidade de sócios, sendo necessárias, para a configuração do grupo, a demonstração do interesse integrado, a efetiva comunhão de interesses e a atuação conjunta das empresas dele integrantes.

Art. $3^{\mathrm{O}}$ - Considera-se empregado toda pessoa física que prestar serviços de natureza não eventual a empregador, sob a dependência deste e mediante salário.

Parágrafo único - Não haverá distinções relativas à espécie de emprego e à condição de trabalhador, nem entre o trabalho intelectual, técnico e manual.
}

Sendo atualmente possível efetuar a contratação de um trabalhador por meio de diversas modalidades, como por exemplo, por tempo parcial, por prazos determinado ou indeterminado, intermitente, temporário ou por experiência e, com maior frequência, em razão de necessidade, estão sendo admitidas fora das condições de 
um ofício formal, sem que sejam observados os princípios básicos do trabalho digno, ou seja, sem que haja o devido respeito aos direitos trabalhistas básicos, sem delimitação de jornada de trabalho, sem a garantia de um salário-mínimo e sem que sejam cumpridas as recomendações de saúde e de segurança no trabalho (SABINO, 2019).

É relevante levar em conta que, neste momento de pandemia de covid-19 causada pelo novo coronavírus, isolar-se socialmente não é viável para todos. Assim, a adoção do termo "Fique em Casa" para as atividades do dia a dia, como forma de evitar o contágio, assim como o exercício do hábito de pedir tudo o que se necessita para entrega em domicílio, é um privilégio de parcas pessoas. Mesmo assim, os serviços de entrega neste momento pandêmico tornaram-se laborações essenciais e tiveram grande crescimento em virtude da demanda cada vez maior. Para se ter uma ideia, a plataforma digital de entrega de alimentos iFood, que atua em mais de mil municípios brasileiros, mais que dobrou o número de inscrições de candidatos para trabalharem como entregadores entre os meses de fevereiro e março de 2020, saltando de 85 mil para 175 mil. 3 Os profissionais de entrega por aplicativos encontram-se totalmente expostos ao risco de contaminação pelo novo coronavírus, acuados pelas próprias necessidades financeiras, os riscos inerentes à função e a desigualdade que caracteriza sua relação com a empresa gestora do aplicativo. Neste cenário, nota-se que o colaborador que efetua entregas por apps em pleno século XXI tem a mesma liberdade do operário da $1^{\mathrm{a}}$ Revolução Industrial, já que atua em ambiente de extremo risco, por muitas horas, a fim de sobreviver. Questiona-se, então, se a concepção de "parceria" com os entregadores alegada pelas plataformas digitais de apps está em consonância com a realidade dos fatos. Isto porque, a atividade exercida em nome da empresa de aplicativos pelos

\footnotetext{
3 Dados publicizados pelo vice-presidente financeiro e estratégico do iFood, Diego Barreto, em entrevista à rede de notícias Reuters, em $1^{\circ}$ de abril de 2020. Ver: "Candidatos a entregador do iFood mais que dobram após coronavírus". Disponível em: <https://br.reuters.com/article/idBRKBN21J6N4-OBRIN $>$. Acesso em $1^{\circ} \mathrm{de}$ outubro de 2020.
} 
encarregados da entrega das compras dos clientes é alegadamente caracterizada pela eventualidade e total autonomia, o que desvincularia a natureza de emprego e desoneraria a plataforma de quaisquer responsabilidades em relação aos perigos suportados pelos colaboradores (MELO, 2020).

Sem dúvidas, a Internet é um enorme catalizador na alteração sistemática das relações de trabalho. $\mathrm{O}$ fato da Rede Mundial de Computadores proporcionar inédita praticidade e agilidade nas relações (sejam elas pessoais, jurídicas, sociais ou políticas), causa, em efeito cascata, a redução da quantidade de contratos de trabalho formais assinados entre empregados e empregadores, ao passo que cria um ambiente de troca veloz de informações, intercâmbio de ideias, entrega de produtos e serviços, colocando diversos agentes econômicos que, antes, dependeriam da estabilização de contratos formais de trabalho para se encaixarem na lógica de mercado, numa posição de "colaboradores" ou "empreendedores".

Assim, ao passo em que assistimos a ampliação da procura por trabalhos informais, vislumbramos que este mesmo trabalho realizado no universo virtual acaba sendo desumanizado de maneira seletiva, já que as companhias que exploram tais mercados como Uber, iFood, 99 Taxi, Rappi, entre outras, não apenas deixariam de existir sem os indivíduos que atuam na manutenção de seus softwares e plataformas, quanto, é claro, se não houvesse pessoas aceitando os pedidos de compras dos utilizadores, os retirando nos estabelecimentos e os entregando aos consumidores finais. A seletividade postulada acima, diz respeito justamente à valorização dos primeiros profissionais como empregados e, dos segundos, como "parceiros".

Outra característica repetida entre os entregadores é a precarização de suas condições de trabalho e o fácil meio de substituição de sua mão de obra. Dessa percepção, surgiu o termo "uberização" da força de trabalho, inserido num pano de fundo em que políticas econômicas neoliberais deram a tônica em países desenvolvidos e subdesenvolvidos. O termo, por sua vez, foi cunhado como uma forma de referenciar as condições de trabalho dos motoristas do app de transporte Uber. 
"Uberizar" as relações de trabalho é alterar substancialmente os meios de atuação no mercado profissional, já que as contratações passam a ser automatizadas ao mesmo tempo em que se prega a concepção de que o trabalhador é o único responsável pelo seu insucesso ou prosperidade. Entende-se que o fenômeno da "uberização" da força de trabalho altera a conjuntura trabalhista global com a mesma relevância do que ocorreu com o Fordismo na década de 1910 e com o Toyotismo na década de 1970 do século $\mathrm{XX}$, fornecendo, estes últimos, uma igualdade de condições para os trabalhadores, embora igualmente apresentasse diversas desconformidades nas conjunções trabalhistas. A "uberização" ocupacional, todavia, é marcada pela não assinatura de contratos formais e da carteira profissional, pelo não estímulo à competição entre os colaboradores e pela não previsão de dias de repouso compulsórios (SOUZA, 2020).

O conceito de "uberização" abrange particularidades do meio do trabalho, já que é encarado pela companhia contratante como uma atividade sem qualquer vínculo trabalhista com o colaborador que a desempenha, há total flexibilidade de jornada diária e toda a responsabilidade pela função exercida, bem como sobre seus meios de executá-la, fica a cargo de quem pratica a tarefa. Desta feita, as corporações detentoras das plataformas web se apresentam como meras oferecedoras da ferramenta usada pelo praticamente do serviço, pelo produtor ou detentor do que será entregue e também pelo usuário cliente final (WEISS, 2019).

Sobre a "uberização" do trabalho, escreveu Abílio (2019, p. 02/03):

Nessa condição de quem adere e não mais é contratado, o trabalhador uberizado encontra-se inteiramente desprovido de garantias, direitos ou segurança associados ao trabalho; arca com riscos e custos de sua atividade; está disponível ao trabalho e é recrutado e remunerado sob novas lógicas.

[...]

As empresas-aplicativo vêm se apresentando como mediadoras entre oferta e procura, negando a subordinação e vínculos empregatícios nessa intermediação. Parte de seu discurso se assenta em um retorno aos pilares do liberalismo: teríamos então agentes 
econômicos independentes que se encontram no mercado e exercem livremente suas potencialidades, o que levaria a um equilíbrio geral entre oferta e procura e à promoção do bem-estar geral.

Nesta direção, antevendo que a modalidade de trabalho informal para plataformas digitais irá se tornar tendência no futuro, a Organização Mundial do Trabalho - OIT publicou o documento "Trabalhar para um futuro melhor", sugerindo que seja aperfeiçoado um mecanismo de supervisão mundial para os meios virtuais, de forma que seja exigido o atendimento de direitos e garantias básicas de trabalho por parte das empresas e também dos próprios usuários clientes. A publicação expôs o exemplo da categoria de marinheiros que é dotada da Convenção do Trabalho Marítimo, que atua como um tipo de código mundial para o desempenho do trabalho da classe. A intensificação da checagem e do monitoramento das atividades desempenhadas é igualmente essencial para que seja alcançada esta meta, afinal somente através dela será possível a eficaz restrição das horas diárias e semanais trabalhadas e do comprometimento em relação às recomendações de segurança e de saúde, essenciais para atingir condições de trabalho digno e humano. Neste diapasão, o debate que envolve temas como o aperfeiçoamento das ciências tecnológicas e a criação de oportunidades de trabalho precisa obrigatoriamente tratar sobre a temática do trabalho digno, da mesma forma que é sustentado pela OIT, afinal apenas garantindo que sejam cumpridas necessidades trabalhistas mínimas é que será atingível uma economia desenvolvida nos moldes da inclusão e da sustentabilidade (SABINO, 2019).

Neste momento, estamos enfrentando uma das maiores dificuldades dos nossos tempos, já que grandes transformações no campo das profissões atingem intrinsecamente todas as sociedades do planeta, ainda mais neste momento em que a humanidade se encontra em luta contra a pandemia de covid-19, causada pelo novo coronavírus. É nesse contexto que novas influências estão modificando tenazmente a esfera do trabalho, como a utilização da inteligência artificial, dos robôs e da automatização, extinguindo e 
criando posições laborativas, de forma que aqueles que se tornarem órfãos de suas ocupações profissionais nesta passagem, de certa forma, serão os menos aptos para abraçarem as oportunidades que virão. Muitas atividades que são desempenhadas hoje não serão mais exercidas amanhã e mesmo as novas funções poderão se tornar ultrapassadas e desnecessárias de maneira muito rápida.

"Crowdwork", que em inglês significa "trabalho da multidão" ou "colaboração em grupo" é uma modalidade de trabalho informal século XXI. Crowdwork diz respeito à realização de encargos através de plataformas online que intermediam a comunicação entre instituições e pessoas, utilizando a Internet, e possibilitam a aproximação entre consumidores e trabalhadores informais de todo o planeta. Assim como outros tipos de labor informal, o crowdwork é qualificado pela inexistência de estabilidade no emprego e poucas (ou nenhuma) garantias e/ou proteções trabalhistas. Acredita-se que os websites que promovem o crowdworking e o trabalho entreposto por apps, que permeiam a economia dos meios digitais, terão o álibi de reinventar os hábitos e costumes do trabalho oriundos do século XIX e criar os futuros trabalhadores virtuais.

Sobre a concepção do crowdworking, registrou Nantal (2018, p. 35):

Esse conceito está incluído, na verdade, em um conceito mais abrangente, chamado de crowdsourcing, uma combinação das palavras 'crowd' e 'outsourcing, para representar a ideia de uma espécie de terceirização 4 para um grande número de pessoas (a 'multidão'). O termo foi introduzido por Jeff Howe em 2006, que o definiu como 'o ato de uma empresa terceirizar uma função até então executada por empregados para uma rede indefinida (e geralmente grande) de pessoas, na forma de um convite aberto', podendo ser realizada colaborativa ou individualmente, desde que observados 'o uso do formato de convite aberto e a grande rede de potenciais trabalhadores'.

4 Nota do original: "A terceirização aqui deve ser entendida de modo amplo, pois não há a figura do empregado terceirizado, da empresa e do tomador; o trabalho é prestado por um público indefinido, não especificamente designado para realizá-lo, daí a diferença entre a terceirização e o crowdsourcing”. 
A partir desta nova concepção de trabalho, com a alteração das cadeias de produção de maneira profunda pelas tecnologias cada vez mais expansivas, é possível notar, como descreveu Nantal na explanação do termo crowdworking, que há uma tendência de superação da necessidade de supervisão do trabalho por uma pessoa remunerada. Neste cenário, funções de gerência, outrora exercidas por indivíduos humanos, passaram a ser exercidas por algoritmos computacionais, que atendem com eficácia e exatidão a incumbência de avaliação de desempenho das atividades cumpridas. É relevante a observação de que o poder de direção da empresa contratante se intensifica com a utilização dos apps, afinal, os programas computacionais acompanham cada acesso dos utilizadores às plataformas digitais, de forma que a empresa possui uma visão completa sobre como se apresenta a demanda pelo serviço que ela oferece e sobre a mão de obra que dispõe. Assim, as novas espécies de trabalho sob supervisão virtual possibilitam maior controle por parte da companhia sobre os trabalhadores, que passam a receber, portanto, uma cobrança maior por parte de sua gerência/chefia e, sobretudo, do próprio software (COSENTINO FILHO, 2017). Aqui é necessário o entendimento do que pesquisadores e estudiosos batizaram de "gig economy", com um conceito que no Brasil poderia se chamar de "economia do bico", que abrange uma já inserida modificação do seio trabalhista totalmente voltado ao ramo de serviços (WEISS, 2019).

O Dicionário de Cambridge conceitua "gig economy" como um modelo de emprego alternativo pautado em pessoas que possuem contratações temporárias ou que desempenham funções laborais na modalidade "freelancer", de maneira eventual, remuneradas separadamente, ao invés de prestarem suas funções a um contratante permanente (THESAURUS, 2020).5 O modo de trabalho tradicional, com desempenho de tarefas em horário e locais fixos, está sendo gradualmente trocado por vinculações variáveis e sem uma única

5 Tradução nossa do original: "gig economy (noun) - a way of working that is based on people having temporary jobs or doing separate pieces of work, each paid separately, rather than working for an employer". 
identidade. A gig-economy gira em torno de trabalhos "on-demand" (sob demanda), pagos pela sua prestação instantânea, sendo possível localizar especialistas em todos os campos de atuação. A função “ondemand' prestada pelo intermédio de apps geralmente está associada ao desempenho de serviços tradicionais, como condução e faxina, bem como atividades administrativas. $\mathrm{O}$ aplicativo então define e assegura um critério de qualidade mínimo no desempenho do serviço ao cliente, além de escolher e supervisionar o trabalhador" (WEISS, 2019).

A passagem para uma nova era das relações do trabalho que respeite o ecossistema e busque conter as alterações climáticas abalará mais ainda o espaço mercadológico do trabalho. $\mathrm{O}$ aumento da parcela de pessoas jovens em determinados locais irá agravar a situação do desemprego e o impulso migratório. Em outros locais, o fato da população se tornar mais velha, arrochará os mecanismos de seguridade e de cuidados sociais. Neste contexto, a criação de vagas de trabalho dignas converteu-se em algo ainda mais dificultoso.

Assim dispôs a OIT no documento intitulado "Trabalhar para um futuro melhor" (ORGANIZAÇÃO INTERNACIONAL DO TRABALHO, 2019):

Potenciar e gerir a tecnologia a favor do trabalho digno. Significa envolver trabalhadores e gestores na negociação da concepção do trabalho. Significa também adotar uma abordagem da inteligência artificial baseada no "ser humano no comando", que garanta que decisões finais que afetem o trabalho sejam tomadas por seres humanos. Deveria estabelecer-se um sistema de governação internacional para as plataformas digitais de trabalho de forma a exigir que estas plataformas (e os seus clientes) respeitem certos direitos e proteções mínimas. Os avanços tecnológicos exigem também a regulação do uso de dados e da responsabilização quanto aos algoritmos usados no contexto do mundo do trabalho.

A "uberização" das ocupações abarca uma espécie de uso da mão de obra laboral que pressupõe a disponibilidade do colaborador para a empresa gestora do software, embora esta o requisite somente no momento que lhe é preciso, de maneira automática e logarítmica. A companhia detentora do app, possui a direção e a faculdade de 
diagramar e esquematizar a força de trabalho e sua procura, que por sua vez também está mapeada pelo software e vinculada a ele. O colaborador fica à mercê da empresa, porém não possui nenhuma possibilidade de diálogo ou negociação com o comando da empresa acerca de sua alocação espacial, da disposição de sua própria força laboral, ou mesmo a respeito da sua valoração. As normas sobre a alocação da atividade, recebimentos e gratificações, comando sobre o preço do desempenho e suas formas alternativas não possuem clareza e nem predefinição. No momento, tem sido utilizada a palavra gamificação, oriunda do termo em inglês game, para dar nome aos métodos de coordenação e organização do novo regime trabalhista mundial. Tal expressão diz respeito ao gerenciamento de normas variáveis que fazem com que a iniciativa ao trabalho seja repleta de riscos e sem quaisquer respaldos. A produção é incentivada e assegurada através de regramentos que demonstram ser verdadeiras aventuras desafiantes para o subalterno, que dizem respeito a possibilidades de premiações e, sobretudo, à indefinição e à dúvida quanto ao alcance da meta perseguida (ABILIO, 2019).

\section{DA NECESSIDADE DE ESTABELECIMENTO DE UM MARCO REgUlatório PARA A PRESTAÇÃo DE SERVIÇOS DE ENTREGA PARA APLICATIVOS}

É importante ressaltar as desmedidas jornadas laborais a que estão submetidos os entregadores, em virtude da falta de controle e proteção legislativa. Em que pese estarem presentes os conceitos defendidos pelas empresas contratantes de flexibilidade dos turnos e de horas trabalhadas por cada colaborador, na realidade o que ocorre é a sujeição às exaustivas jornadas de trabalho, muitas vezes passando de 12 horas diárias (MACHADO, 2020), o que nos faz relembrar das 
circunstâncias de trabalho do começo da era industrial moderna, quando a pequena produção artesanal de manufaturas deu espaço à enorme produção de cunho capitalista e, ao seu lado, o aproveitamento abusivo do trabalho assalariado. Em muitas ocasiões, aqueles que trabalham como entregadores para aplicativos enfrentam extensas horas de trabalho para obter uma remuneração mínima para sua subsistência.

A modalidade de trabalho de entrega por aplicativos obteve status de ainda maior relevância diante do assolamento da pandemia de covid-19, causada pelo novo coronavírus, e da consequente prática do isolamento social pela maioria das pessoas, passando a ser considerada um serviço essencial. ${ }^{6} \mathrm{O}$ que se verificou foi um acréscimo excessivo da demanda dos serviços prestados pelas companhias detentoras dos apps de entregas, enquanto seus colaboradores passaram a trabalhar por mais horas e com redução de suas remunerações. Tal cenário, ao lado da falta de proteções à saúde e segurança dos entregadores em relação aos riscos oferecidos pela pandemia de covid-19, denunciam a deterioração e precariedade das condições de trabalho dos profissionais de entrega do setor. Sabe-se que as companhias gestoras dos apps de delivery conservam elevado sigilo dos dados que dizem respeito ao número de entregadores cadastrados, seus perfis sociais e econômicos e os critérios de remunerações. Assim sendo, não é de conhecimento público quais são os critérios de distribuição de atividades e nem qual é a sistemática que define os valores das entregas e suas bonificações. Tampouco se sabe sobre os parâmetros utilizados para o desligamento de colaboradores (ABILIO, 2020).

O principal argumento das empresas detentoras dos aplicativos de delivery para afastar a relação de emprego entre os trabalhadores de entrega e, consequentemente, os encargos trabalhistas que esta

\footnotetext{
${ }^{6}$ Os serviços de "produção, distribuição, comercialização e entrega, presenciais ou por meio do comércio eletrônico, de produtos de saúde, higiene, limpeza, alimentos, bebidas e materiais de construção" foram considerados essenciais pelos Decretos $\mathrm{n}^{\mathrm{o}}$ 10.282, de 20 de março de 2020 e $\mathrm{n}^{0}$ 10.392, de 28 de abril de 2020.
} 
relação empregatícia acarretaria, é a eventualidade da prestação de serviços, de forma que, segundo elas, não se configura a situação de emprego contida no artigo $3^{\circ}$ da CLT. A ausência de regulação para direcionar a performance dos aplicativos de entrega está alterando o funcionamento de todo o mercado de trabalho, fixando situações de desempenho de atividades laborais dotadas de plena subordinação, porém carentes de direitos e garantias trabalhistas (AMORIM, 2020).

Desse modo, nos mesmos moldes em que se tornou necessária na Europa pós- Revolução Industrial, no Brasil da Era Vargas e no conjunto dos demais países, em menor ou maior grau, uma regulação mais clara, protetiva e garantidora de regimes dignos de trabalho a partir do nascimento e expansão de companhias que minimizam a individualidade e o humanismo em nome do lucro, os novos meios de trabalho virtual deverão passar nos próximos anos pelo mesmo movimento regulatório. Este movimento de pressão e estiramento da corda que liga a classe trabalhadora da base da cadeia produtiva de aplicativos de entrega com as grandes corporações do setor já começou, com manifestações e paralisações dos serviços em São Paulo, Belo Horizonte, Brasília, Fortaleza, Salvador, Recife e outras cidades (RIBEIRO, 2020).

É importante notar que o poder público não tem sido absolutamente negligente com a crescente demanda dos serviços de aplicativos, sendo certo que diversas cidades e até mesmo países que passam pela introdução da "uberização" realizaram regulações de ordem tributária e de garantia de segurança. Ao mesmo tempo, a resolução das pendências trabalhistas que envolvem o tema não parece ser assunto confortável de ser debatido pelos gestores públicos ao redor do mundo, especialmente em um momento em que há a percepção de que a lógica do teletrabalho e do trabalho "on demand" por apps será implantada nos mais diversos ramos da cadeia produtiva, criando pressões, lobby e influência de grandes players econômicos. É perceptível que outros temas que circundam as relações de trabalho por apps já foram regulados em grandes metrópoles como São Paulo, Londres ou Madri e que existem Projetos de Lei em 
tramitação no Congresso Nacional brasileiro versando sobre o tema, mas em nenhuma dessas menções a precarização do trabalho e as más condições de vida e emprego dos funcionários/entregadores é o foco principal das discussões.

\section{CONCLUSÃo}

Como foi abordado ao longo do texto, a “uberização" é um fenômeno presente na sociedade brasileira e mundial, especialmente nos grandes centros urbanos. Esta prática de virtualização das relações de trabalho, acompanhada da redução ou mesmo anulação de todo e qualquer tipo de direito trabalhista ou garantia de dignidade para os participantes da cadeia produtiva parece acompanhar a lógica de uma nova Revolução Industrial, dessa vez digital.

Do mesmo modo que a Inglaterra no final do século XIX estabeleceu ao mundo novas formas de organização das forças produtivas, colocando as vidas, a dignidade humana e o bem-estar social em segundo plano, o século XXI passa por um novo momento de desequilíbrio massivo das relações entre trabalhadores e patrões. Trata-se de reedição do progresso capitalista predatório que amplifica a capacidade de corporações em criarem e manterem seus lucros, mesmo que isso custe a asfixia da dignidade de sua mão-de-obra. Este desequilíbrio será visto não apenas no trabalho imediato, mas nas discussões previdenciárias, na implantação de sistemas de saúde e dos demais serviços públicos que, em longo prazo, serão impactados significativamente pela nova lógica de trabalho no mundo.

A partir da análise do estado da arte que vivenciamos neste momento, especialmente durante a pandemia do novo coronavírus em que as implicações trabalhistas aos entregadores de aplicativos se tornaram ainda mais graves, se faz mandatório e urgente o debate para a instauração de um sistema regulatório para o setor que represente 
segurança e estabilidade para esta nova classe de trabalhadores, tanto quanto a CLT já representou para os empregados urbanos durante a Era Vargas. É possível concluir também, sem olvidar do papel abrangente daquele que se debruça sobre as relações sociais, que o Estado já trabalha em modelos de regulação dos novos serviços de aplicativos em frentes tributárias, ambientais ou de segurança pública, mas não parece acompanhar com o mesmo afinco e profundidade um debate sério sobre a criação de um marco regulatório trabalhista para o setor.

Data de Submissão: 29/07/2020

Data de Aprovação: 22/10/2020

Processo de Avaliação: double blind peer review

Editor Geral: Jailton Macena de Araújo

Editor de Área: Jailton Macena de Araújo

Assistente Editorial: Rafael Câmara Norat

\section{REFERÊNCIAS}

ABILIO, Ludmila Costhek. Uberización: de la iniciativa empresarial a la autogestión subordinada. Psicoperspectivas. Individuo y

Sociedad, [S.L.], v. 18, n. 3, 15 nov. 2019. Pontificia Universidad Catolica de Valparaiso. http://dx.doi.org/10.5027/psicoperspectivasvol18-issue 3 -fulltext-1674.

ABÍLIO, Ludmila Costhek; ALMEIDA, Paula Freitas de; AMORIM, Henrique; CARDOSO, Ana Claudia Moreira; FONSECA, Vanessa Patriota da; KALIL, Renan Bernardi; MACHADO, Sidnei. Condições de trabalho de entregadores via plataforma digital durante a COVID19. Revista Jurídica Trabalho e Desenvolvimento Humano, [S.L.], v. 3, p. 1-21, 8 jun. 2020. Revista Jurídica Trabalho e Desenvolvimento Humano. http://dx.doi.org/10.33239/rjtdh.v.74. 
AMORIM, Henrique; MODA, Felipe Bruner. Trabalho por aplicativo: gerenciamento algorítmico e condições de trabalho dos motoristas da Uber. Fronteiras - Estudos Midiáticos, [S.L.], v. 22, n. 1, p. 1-12, 14 mar. 2020. UNISINOS - Universidade do Vale do Rio Dos Sinos. http://dx.doi.org/10.4013/fem.2020.221.06.

ARAUJO, Ygor Leonardo de Sousa. Uberização do trabalho: a relação empregatícia entre os entregadores e as empresas de aplicativos de comida. 2019. 42 f. TCC (Graduação) - Curso de Direito, Direito do Trabalho; Processo do Trabalho, Universidade Federal de Pernambuco, Recife, 2019.

ARENDT, Hannah. A Condição Humana. 10. ed. Rio de Janeiro: Forense, 2007. Trad. por Roberto Raposo.

BRASIL. Congresso. Câmara dos Deputados. Decreto-Lei no ${ }^{0}$ 5.442, de 1 de maio de 1943. Consolidação das Leis do Trabalho. Brasília, DF, 1 maio 1943. Disponível em: http://www.planalto.gov.br/ccivil 03/decreto-lei/del5452.htm. Acesso em: 16 jul. 2020.

CARVALHO, José Murilo de. Cidadania no Brasil: o longo caminho. 3. ed. Rio de Janeiro: Civilização Brasileira, 2002. Disponível em: https://necad.paginas.ufsc.br/files/2012/o7/CARVALHOJos\%C3\%A9-Murilo-de.-Cidadania-no-Brasil1.pdf. Acesso em: 01 out. 2020.

COSENTINO FILHO, Carlo Benito. O direito do trabalho na revolução informacional e nas teorias dos movimentos sociais: impactos no postulado autonomia, nas relações individuais e coletivas de trabalho. 2017. 370 f. Tese (Doutorado) - Curso de Direito, Centro de Ciências Jurídicas/faculdade de Direito do Recife da Universidade Federal de Pernambuco, Universidade Federal de Pernambuco, Recife, 2017.

FLEURY, Maria Tereza Leme. Trabalho e labor no mundo digital. Revista GV Executivo, São Paulo, v. 2, n. 19, p. 1-1, maio 2020. Disponível em: http://bibliotecadigital.fgv.br/ojs/index.php/gvexecutivo/article /viewFile/81618/77876. Acesso em: o1 out. 2020.

LEITE, Carlos Henrique Bezerra. Curso de direito do trabalho. 9. ed. São Paulo: Saraiva, 2018.

MACHADO, Leandro. Dormir na rua e pedalar 12 horas por dia: a rotina dos entregadores de aplicativos. BBC News Brasil. São Paulo. 22 maio 2019. Disponível em: 
http://www.bbc.com/portuguese/brasil-48304340. Acesso em: 01 out. 2020.

MARTINEZ, Luciano. Curso de Direito do Trabalho: relações individuais, sindicais e coletivas do trabalho. São Paulo: Editora Saraiva, 2015.

NANTAL, Carine Pandolfo. O Direito do Trabalho no Contexto da Gig Economy: análise da (in)suficiência da estrutura típica da relação de emprego diante das formas de trabalho emergentes. 2018. 92 f. TCC (Graduação) - Curso de Direito, Universidade Federal do Rio Grande do Sul, Porto Alegre, 2018. Disponível em: https://www.lume.ufrgs.br/bitstream/handle/10183/190064/o 0108766. pdf. Acesso em: o1 out. 2020.

NASCIMENTO, Amauri Mascaro; NASCIMENTO, Sônia Mascaro. Curso de Direito do Trabalho. 29. ed. São Paulo: Saraiva, 2014.

ORGANIZAÇÃO INTERNACIONAL DO TRABALHO

OIT. Trabalhar para um futuro melhor. Lisboa: OIT, 2019. Disponível em: https://www.ilo.org/wcmsp5/groups/public/--europe/---ro-geneva/---ilolisbon/documents/publication/wcms 677383.pdf. Acesso em: 18 jul. 2020.

RIBEIRO, Gabriel Francisco. Greve não para apps, mas mostra força de entregadores: nova data é votada. UOL. São Paulo, p. 1-2. jul. 2020. Disponível

em: https://ww w.uol.com.br/tilt/noticias/redacao/2020/o7/01/gre ve-nao-para-apps-mas-afeta-sistema-e-mostra-forca-deentregadores.htm. Acesso em: 27 jul. 2020.

SANTOS, Wanderley Guilherme dos. Cidadania e Justiça: a política social na ordem brasileira. Rio de Janeiro: Campos, 1979.

SÃO PAULO. André Monici Sabino. Tribunal Regional do Trabalho da $15^{\text {a }}$ Região. O Trabalho Decente nas Plataformas Digitais. Campinas: Escola Judicial do TRT da 15 ${ }^{\mathrm{a}}$ Região, 2019. 25 p.

SILVA, Cássia Cristina Moretto da. A proteção ao trabalho na Constituição Federal de 1988 e a adoção do permissivo flexibilizante da legislação trabalhista no Brasil. Constituição, Economia e Desenvolvimento: Revista da Academia Brasileira de Direito Constitucional, Curitiba, v. 4, n. 7, p. 1-28, ago. 2013.

SOUZA, Laura Feijó de. Trabalhadores informais de aplicativos e o impacto da doença pelo novo coronavírus: uma reflexão teórica / informal app workers and the impact of disease by the new coronavirus. Journal Of Nursing And Health, [S.L.], v. 10, n. 4, 
p. 1-16, 1 jun. 2020. Universidade Federal de

Pelotas. http://dx.doi.org/10.15210/jonah.v10i4.18740.

THESAURUS, Cambridge Advanced Learner'S Dictionary \&. Gig economy. Cambridge: Cambridge University Press, 2020.

Disponível

em: https://dictionary.cambridge.org/us/dictionary/english/gigeconomy. Acesso em: 19 jul. 2020.

WEISS, Henrique Chevrand. O céu é o limite: trabalho uberizado e governamentalidade neoliberal nos entregadores-ciclistas em porto alegre. 2019. 64 f. TCC (Graduação) - Curso de Ciências Sociais, Instituto de Filosofia e Ciências Humanas, Universidade Federal do Rio Grande do Sul, Porto Alegre, 2019. Disponível em: http://hdl.handle.net/10183/206588. Acesso em: 01 out. 2020.

WERNER, Regina Célia Diniz. Cidadania no Brasil: o longo caminho. Revista de Administração Contemporânea, [S.L.], v. 9, n. 1, p. 246-246, mar. 2005. FapUNIFESP (SciELO). http://dx.doi.org/10.1590/s1415-65552005000100015. 


\title{
The Precariousness On Apps' Delivery Drivers Work Conditions
}

\author{
Felipe Labruna
}

Alvaro de Azevedo Gonzaga

Marco Aurélio Barreto Lima

\begin{abstract}
This scientific article intends to deepen the discussions about the phenomenon of the transformation of labor relations through digital platforms ("applications" or "apps") and the consequent precariousness of work conditions and degradation of the social rights of delivery drivers, bringing new elements in order to propose a concise regulatory environment that takes on the new difficulties brought by those technologies. This technological change concerns an innovative worldwide trend of administration, management and dominance of labor relations in virtual environments, causing a harmful effect to the delivery worker known as the "uberization" of his workforce. That said, this paper aims to do a brief legislative research on Labor Law's history of concession and regulation in Brazil and to analyze, by using a theoretical approach, how the work through the mentioned digital platforms/applications demands a greater state regulation of its practice and use.
\end{abstract}

Keywords: Delivery apps. Delivery drivers. Labor law. Social rights. "Uberization”.

DOI: $\underline{\text { https://doi.org/10.22478/ufpb.1678-2593.2021v20n43.54209 }}$

Conteúdo sob licença Creative Commons: Attribuition-NonCommercial-NoDerivative 4.o International (CC BY-NC-ND 4.0)

(cc) BY-NC-ND 